\title{
Copper Cu 62-ATSM
}

National Cancer Institute

\section{Source}

National Cancer Institute. Copper Cu 62-ATSM. NCI Thesaurus. Code C113441.

A radioconjug ate consisting of a lipophilic, neutral, bioreductive copper-

bis(thiosemicarbazone) complex, copper-diacetyl-bis(N4-methylthiosemicarbazone) (CuATSM), labeled with the beta-emitting radioisotope copper Cu 62, with hypoxia-selective and positron emitting tomog raphy (PET) radioimaging activities. With a high membrane permeability and low reduction potential, copper Cu 62-ATSM easily enters cells. This agent can only be reduced by mitochondria found in hypoxic cells with abnormally high electron concentrations. This chemical reaction traps Cu 62-ATSM in the cell, which allows for the selective accumulation of this agent in hypoxic cells compared to normoxic cells. The extent of copper Cu 62-ATSM retention in tissue is inversely related to the state of tissue oxygenation allowing the quantitation of tissue hypoxia with PET. This provides information about diagnosis, prognosis, treatment options and outcomes for certain cancers. The short half-life of copper Cu 62 (9.7 minutes) reduces the amount of radiation a patient is subjected to and allows for several imaging studies to be performed. Hypoxic tumors are associated with increased malignancy and resistance to radiation and chemotherapy. 